\title{
Os conselhos de saúde e a publicização dos instrumentos de gestão do SUS: uma análise dos portais das capitais brasileiras
}

\author{
Health councils and dissemination of SUS management \\ instruments: an analysis of portals in Brazilian capitals
}

Christiane Luiza Santos (https://orcid.org/0000-0002-8299-455X) ${ }^{1}$

Paloma Maria Santos (https://orcid.org/0000-0001-6660-5270) ${ }^{2}$

Huascar Fialho Pessali (https://orcid.org/0000-0002-5770-4653) ${ }^{3}$

Aires José Rover (https://orcid.org/0000-0003-1070-5357) ${ }^{4}$

\footnotetext{
${ }^{1}$ Faculdades Pequeno Príncipe. Av. Iguaçu 333, Rebouças. 80230020 Curitiba PR Brasil. aluizachris@gmail.com ${ }^{2}$ Departamento

de Engenharia do Conhecimento, Centro Tecnológico, Universidade Federal de Santa Catarina.

${ }^{3}$ Departamento de Economia, Universidade Federal do Paraná. Curitiba PR Brasil.

${ }^{4}$ Centro de Ciências Jurídicas, UFSC.

Florianópolis SC Brasil.
}

\begin{abstract}
Coparticipants in the performance, planning, and control of public policies' implementation, Health Councils are public spaces aiming at the participation and social control of health actions concerning the community. Access to information is a crucial condition so that not only advisers but also civil society can propose, monitor, and evaluate the actions taken in health. Based on this understanding and the guidance provided by Law $N^{\circ} 141 / 2012$ on the visibility of SUS management instruments, this study aimed to verify how the municipal portals of Brazilian capitals have disseminated their Health Councils and the necessary instruments for analyzing, monitoring, and following-up on the health policy. While recommended by law, the research showed that dissemination occurs differently between capitals. Only $14 \%$ of the investigated portals make SUS management instruments available on the council pages, and 33\% do not disclose information about the council or management instruments. The lack of such content can weaken the council's institutionality and, ultimately, participatory democracy itself.
\end{abstract}

Key words Health council, Access to information, Planning instrument, Participation and social control
Resumo Coparticipantes na atuação, planejamento e controle da execução de políticas públicas, os conselhos de saúde constituem espaços públicos que objetivam a participação e o controle social das ações em saúde que dizem respeito à coletividade. $O$ acesso à informação é uma condição imprescindivel para que não só conselheiros, mas a sociedade civil como um todo, possa propor, monitorar e avaliar as ações empreendidas na área da saúde. A partir desse entendimento e da orientação advinda da Lei 141/2012 sobre dar visibilidade aos instrumentos de gestão do SUS, o presente estudo buscou verificar como os portais das prefeituras das capitais brasileiras têm divulgado seus conselhos de saúde e os instrumentos necessários para a análise, o monitoramento e o acompanhamento da política de saúde. Apesar de recomendada por lei, a pesquisa mostrou que a publicidade é dada de distintas maneiras pelas capitais. Apenas $14 \%$ dos portais investigados disponibilizam nas páginas dos conselhos os instrumentos de gestão do SUS e 33\% deles não divulgam nem informações sobre o conselho nem sobre os instrumentos de gestão. A ausência de tais conteúdos pode levar ao enfraquecimento da institucionalidade do conselho e, com isso, da própria democracia participativa.

Palavras-chave Conselho de saúde, Acesso à informação, Instrumento de planejamento, Participação e controle social 


\section{Introdução}

"The Brazilian Unified Health System is a powerful force for equity. The fact that all services and products, including medicines and vaccines, are provided free of charge is a strong foundation not only for better health, but for development. It's also very impressive that ordinary citizens have a voice in shaping the health services that are delivered to them. The fact that community-based health councils are involved in approving health plans is a model for other countries to follow".

No discurso em epígrafe, o Dr. Tedros Ghebreyesus $^{1}$ se refere à participação cidadã e à prática de controle social instituídas no sistema público de saúde brasileiro desde a Constituição Federal, proclamada em 1988. Dentre os mecanismos de participação popular na saúde, destacam-se os conselhos de saúde, uma inovação institucional já reconhecida no mundo acadêmico ${ }^{2-5}$. Eles foram instituídos como uma instância colegiada deliberativa e locus permanente do diálogo entre Estado e Sociedade na política de saúde nos níveis federal, estadual e municipal ${ }^{6}$. Os 5633 conselhos de saúde atualmente existentes no Brasil (5.569 conselhos municipais, 26 estaduais, do Distrito Federal e 36 conselhos distritais) ${ }^{7}$ têm, pela lei, as funções de formular estratégias, controlar e fiscalizar a execução da política de saúde, inclusive nos aspectos econômicos e financeiros $\left(\right.$ art. $\left.1^{\circ}, \$ 20^{8}\right)$.

Em que pese o caráter deliberativo desses espaços, é consensual a percepção dos teóricos sobre as dificuldades existentes para que os conselhos efetivem a participação dos cidadãos na política de saúde, tal como almejado na Constituição ${ }^{5,9-11}$.

Além da baixa incidência dos conselhos na política de saúde $\mathrm{e}^{10,12-14}$ e do uso excessivo de linguagem técnica nas reuniões ${ }^{15-18}$, nesse domínio, diversos são os resultados de pesquisas que apontam restrições de acesso às informações necessárias para a tomada decisão ou ainda desconhecimento dos instrumentos de gestão que regem a política de saúde $\mathrm{e}^{19-25}$.

A informação, além de promover escolhas mais qualificadas, permite, numa perspectiva individual, a realização de um conjunto de direitos - entre eles o da saúde. Nesse sentido, pode-se assumir que "o acesso à informação é um direito que antecede todos os outros" e dá condições para que estes sejam reivindicados ${ }^{26}$, sendo, portanto, condição sine qua non para a democracia, para a redistribuição de recursos de poder e para a democratização do Estado $26,27$.

$\mathrm{O}$ acesso à informação é um direito difuso, que pertence à coletividade, sendo que no contexto público pode resultar em ganhos para a comunidade de forma geral. Ou seja,

conhecer as informações em poder do Estado permite o monitoramento da tomada de decisões pelos governantes - que afetam a vida em sociedade. O controle social mais atento dificulta o abuso de poder e a implementação de políticas baseadas em motivações privadas ${ }^{26}$.

Garantido pela Constituição brasileira (os artigos $5^{\circ}$, inciso XXXIII, $37, \S 3^{\circ}$, inciso II e $216, \S$ $2^{\mathrm{o}^{28}}$ ) e regulamentada pela $\mathrm{Lei}^{\circ} 12.527$, de 2011, a Lei de Acesso à Informação ${ }^{29}$, a efetivação do direito do acesso à informação requer que os atores públicos divulguem e deem transparência às informações que estão sob sua posse. É preciso reconhecer, contudo, que, por vontade própria, os governantes não têm incentivos suficientes para disseminar informações que possam ser contrárias aos seus interesses ou ainda que permitam questionamentos públicos e cobranças, o que demonstra a necessidade de aprovação e implementação de leis que definam procedimentos e prazos para a divulgação de informações, assim como responsabilidades pelo descumprimento desta obrigação ${ }^{26}$.

No contexto da Política de Saúde, a legislação normatiza o direito à informação desde a lei 8080/90 e as legislações posteriores versam sobre a necessidade de se dar transparência às ações do Estado.

\section{A gestão compartilhada e o papel dos conselhos}

Uma das formas utilizadas pela política pública de saúde no Brasil para disponibilizar informação para a sociedade é por meio de documentos de gestão do Sistema Único de Saúde (SUS). As leis que regem o SUS incorporaram tais instrumentos de forma a orientar a alocação dos recursos públicos, dar visibilidade às ações do governo e informar a sociedade das intenções do Estado para a Política de Saúde.

$\mathrm{Na}$ atualidade a gestão do SUS é regida pela Portaria no 2.135 de 25 de setembro de 2013, que define que a Política de Saúde é sintetizada em três principais documentos: i) o Plano de Saúde (PS), que é o instrumento central de planejamento para definição e implementação de todas as iniciativas no âmbito da saúde de cada esfera da gestão do SUS para o período de quatro anos 
e explicita os compromissos do governo para o setor saúde e reflete, a partir da análise situacional, as necessidades de saúde da população e as peculiaridades próprias de cada esfera; ii) a Programação Anual de Saúde (PAS), que é o instrumento que operacionaliza as intenções expressas no Plano de Saúde e tem por objetivo anualizar as metas do Plano de Saúde e prever a alocação dos recursos orçamentários a serem executados; e c) o Relatório Anual de Gestão (RAG), que é o instrumento de gestão com elaboração anual que permite ao gestor apresentar os resultados alcançados com a execução da PAS e orienta eventuais redirecionamentos que se fizerem necessários no Plano de Saúde. A Portaria traz ainda em seu texto a necessidade de transparência e visibilidade por meio do incentivo à participação popular ${ }^{30}$.

No intuito de aumentar a accountability do Estado em relação à política de saúde, a Lei Federal no 141 de 2012 estabelece que os conselhos de saúde passam a ter uma posição mais proeminente no ciclo de gestão do SUS de forma que os conselhos têm a prerrogativa de avaliar e emitir parecer conclusivo (até vetar) o RAG e, ainda, a legislação do SUS e dos Conselhos normatizam que os conselhos apreciem e aprovem tanto o PS como a $\mathrm{PAS}^{31}$.

A Lei 141/2012 discorre ainda que os municípios deverão dar ampla divulgação às prestações de contas da área da saúde para consulta e apreciação da população ${ }^{31}$. Já a Portaria GM/MS no 575, de 29 de março de 2012, estabelece que os todos os instrumentos de gestão do SUS (PS, PAS e RAG) devem ser obrigatoriamente disponibilizados para acesso público no Sistema de Apoio ao Relatório de Gestão (SARGSUS), disponível em www.saude.gov.br/sargsus ${ }^{32}$.

Apesar da obrigatoriedade estar vinculada ao Sistema SARGSUS, entende-se que é papel e obrigação de todas as esferas administrativas promover a transparência e a visibilidade por meios eletrônicos de fácil acesso público, tendo em vista cumprir o direito à informação, participação e controle por instituições, usuários e cidadãos $^{33}$.

Apesar da importância destes instrumentos, estudos trazem que, por vezes, eles são desconhecidos dos conselheiros de saúde, em especial, os representantes dos usuários ${ }^{24,25}$.

Em que pese o fato de existir há quase 30 anos como loci de controle social e reinvindicação para a saúde, estudos apontam um certo desconhecimento da população sobre o papel do conselho de saúde $e^{25,34,35}$. Outros trazem a percepção dos conselheiros de que o conselho não tem visibilidade nem o apoio da população em geral, ficando, por vezes, centrado nas entidades de organização civil que estão envolvidas ${ }^{25,34}$. Demo ${ }^{36}$ acredita que a visibilidade dos conselhos, materializada pela criação de canais de comunicação com a população, é um fator decisivo para a prática democrática.

Tendo em vista ampliar a transparência e garantir a visibilidade à informação, os portais dos municípios, face a sua capilaridade e facilidade de acesso $^{27}$, representam a inserção de um novo elemento na relação entre governo e cidadão e configuram uma iniciativa na busca da implantação da governança, agregando dados e informações que condicionam o cidadão a tomar o seu lugar de direito nos espaços de cidadania ${ }^{37}$.

A partir do entendimento da importância da informação para o exercício da cidadania, da percepção de baixa visibilidade dos conselhos de saúde e do desconhecimento dos conselheiros a respeito dos instrumentos de gestão do SUS, sob os quais os conselhos têm a prerrogativa e a responsabilidade objetiva ${ }^{38}$, este estudo buscou levantar como os portais institucionais das prefeituras das capitais dos estados brasileiros têm publicizado não só seus conselhos de saúde como também os instrumentos de gestão do SUS necessários para o exercício da participação da sociedade na política de saúde.

\section{Metodologia}

A presente pesquisa buscou analisar em que medida os portais das capitais das 27 UFs do Brasil têm veiculado seus conselhos de saúde e cumprem o disposto na Lei 141/2012 quanto à publicização dos instrumentos de gestão do SUS (PS, PAS e RAG).

A avaliação dos portais foi realizada em dezembro de 2017 e foram considerados os endereços eletrônicos oficiais das capitais, conforme disposto no Quadro 1.

Os seguintes aspectos foram considerados: a) se a página da secretaria de saúde sitiada no portal da prefeitura possuía uma página para o conselho municipal de saúde; b) quais informações a página do conselho disponibilizava; c) se os instrumentos de gestão estavam disponíveis na página do conselho; e d) se os instrumentos de gestão estavam na página da secretaria de saúde, caso não estivessem na do conselho.

A escolha da página da secretaria de saúde como locus base para direcionamento à página do conselho de saúde, se dá pelo fato dos con- 
Quadro 1. URL dos portais das capitais consultadas.

\begin{tabular}{|l|l|}
\hline \multicolumn{1}{|c|}{ Capital (UF) } & \multicolumn{1}{c|}{ URL utilizadas } \\
\hline Manaus (AM) & http://www.manaus.am.gov.br/ \\
\hline Boa Vista (RR) & https://www.boavista.rr.gov.br/ \\
\hline Porto Velho (RO) & https://www.portovelho.ro.gov.br/ \\
\hline Rio Branco (AC) & http://www.pmrb.ac.gov.br/ \\
\hline Belém (PA) & http://www.belem.pa.gov.br/ \\
\hline Macapá (AP) & http://macapa.ap.gov.br/ \\
\hline Palmas (TO) & http://www.palmas.to.gov.br/ \\
\hline Maceió (AL) & http://www.maceio.al.gov.br/ \\
\hline Salvador (BA) & http://www.salvador.ba.gov.br/ \\
\hline Fortaleza (CE) & https://www.fortaleza.ce.gov.br/ \\
\hline São Luis (MA) & www.saoluis.ma.gov.br \\
\hline João Pessoa (PB) & http://www.joaopessoa.pb.gov.br/ \\
\hline Recife (PE) & http://www2.recife.pe.gov.br/ \\
\hline Teresina (PI) & http://www.teresina.pi.gov.br/ \\
\hline Natal (RN) & https://natal.rn.gov.br/ \\
\hline Aracaju (SE) & http://www.aracaju.se.gov.br/ \\
\hline Goiânia (GO) & https://www.goiania.go.gov.br/ \\
\hline Cuiabá (MT) & http://www.cuiaba.mt.gov.br/ \\
\hline Campo Grande (MS) & http://www.campogrande.ms.gov.br/ \\
\hline Distrito Federal & http://www.df.gov.br/ \\
\hline Vitória (ES) & http://www.vitoria.es.gov.br/ \\
\hline Belo Horizonte (MG) & https://prefeitura.pbh.gov.br/ \\
\hline São Paulo (SP) & http://www.capital.sp.gov.br/ \\
\hline Rio de Janeiro (RJ) & http://www.rio.rj.gov.br/ \\
\hline Curitiba (PR) & http://www.curitiba.pr.gov.br \\
\hline Florianópolis (SC) & http://www.pmf.sc.gov.br/ \\
\hline Porto Alegre (RS) & http://www2.portoalegre.rs.gov.br/portal_pmpa_novo/ \\
\hline & \\
\hline
\end{tabular}

selhos fazerem parte da estrutura organizacional destas secretarias e, ainda, serem de responsabilidade destas o suporte físico e operacional dos conselhos ${ }^{28,31,39}$.

A análise dos portais se deu de duas formas (Figura 1): os principais instrumentos de gestão do SUS (PS, PAS e RAG) foram buscados na página do Conselho Municipal de Saúde, disposta dentro da página da Secretaria de Saúde do município (Fluxo 1). Caso não fossem encontrados, seriam então buscados diretamente na página da Secretaria Municipal de Saúde (Fluxo 2).

Se porventura os instrumentos de gestão do SUS não estivessem disponíveis nem na página do Conselho (Fluxo 1) nem da Secretaria de Saúde (Fluxo 2), uma terceira busca seria realizada empregando o mecanismo de busca do portal da Prefeitura utilizando os descritores "conselho municipal de saúde", "plano municipal de saúde", "relatório anual de gestão", "programação anual de saúde". Em relação à busca realizada para o
Distrito Federal, o descritor "municipal" foi substituído por "distrital".

Vale salientar que quando nenhuma menção ao Conselho de Saúde era feita na página da Secretaria de Saúde, foi utilizado o mecanismo de busca Google para verificar se o Conselho de Saúde possuía uma página externa ao portal da Prefeitura da cidade. Nesse caso, foi utilizado o descritor "conselho municipal de saúde de <nome da cidade>", tendo sido selecionado o primeiro resultado advindo desta operação, sempre que coerente com o apontado no ambiente institucional.

Os resultados encontrados foram tabulados e divididos em cinco categorias (I, II, III, IV e V). Elas indicam, em ordem crescente, a disponibilização das informações dentro do espaço virtual reservado aos Conselhos Municipais de Saúde, o locus instituído por lei para avaliação e aprovação dos instrumentos centrais de gestão da política de saúde local. As categorias indicam que o portal 

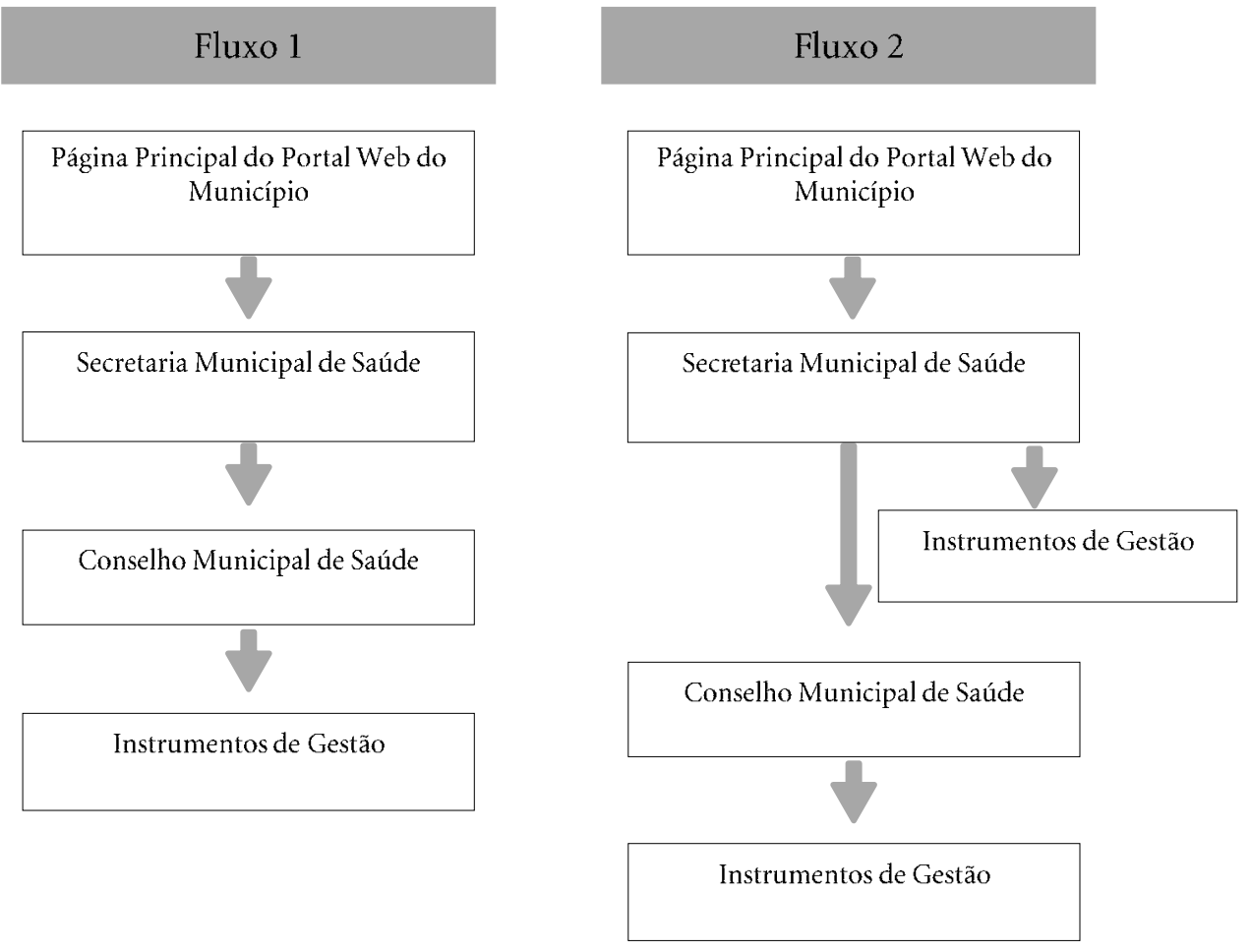

Figura 1. Representação dos fluxos de análise dos portais.

(página da Secretaria de Saúde): (I) não disponibilizava nem uma página sobre o Conselho de Saúde nem os instrumentos de gestão; (II) disponibilizava uma página sobre o Conselho de Saúde mas não os instrumentos de gestão, verificados tanto na página do Conselho quanto na da Secretaria de Saúde; (III) não disponibilizava uma página do Conselho mas os instrumentos de gestão na página da Secretaria de Saúde, (IV) disponibilizava uma página para o Conselho de Saúde e os instrumentos de gestão na página da Secretaria de Saúde; e (V) disponibilizava uma página para o Conselho de Saúde e os instrumentos de gestão dentro da página do Conselho de Saúde.

Tendo em vista avaliar a extensão da transparência buscada pelos gestores locais da saúde, comparou-se, adicionalmente, a postagem dos instrumentos feita nos portais [que não é obrigatória, mas permite maior visibilidade] com a do sistema SARGSUS [que é obrigatória por lei para o instrumento RAG]. No sistema SARGSUS foram buscados os instrumentos de gestão referentes ao ano de 2016, dada a possibilidade de observar o ciclo fechado de planejamento mais recente do SUS - o PMS 2013-2017, o RAG de 2015, e o PAS 2017.

\section{Resultados}

A análise dos resultados mostrou que mais da metade dos portais das capitais $(63 \%$ do universo pesquisado) apresentava uma página específica para o Conselho de Saúde. Dentre os portais que disponibilizaram uma página para $\mathrm{o}$ Conselho, somente quatro (14\%) apresentavam os instrumentos de gestão na página do próprio Conselho (categoria V), em cinco deles (19\%) os instrumentos estavam na página da Secretaria de Saúde (categoria IV) e em oito (29\%) não foram encontrados os instrumentos de gestão em nenhuma delas (categoria II).

Dez capitais não tinham uma página específica para o Conselho de Saúde, sendo que, destas, nove também não apresentavam os instrumentos de gestão na página da Secretaria de Saúde (ca- 
tegoria I) e uma apresentava os instrumentos de gestão na página da Secretaria de Saúde (categoria III). As Figuras 2 e 3 sintetizam os resultados encontrados.

Vale ressaltar que o município de Curitiba foi enquadrado na categoria $\mathrm{V}$, posto que os PAS de 2016 e de 2017 foram encontrados na página das Atas do conselho municipal de Saúde e disponibilizados por meio de link de fácil visualização. Já o município de Florianópolis foi alocado na categoria IV, pois não se conseguiu acessar da mesma forma o PAS na página do conselho, mas sim na página da secretaria de saúde.

Dentre os 17 municípios que apresentavam uma página específica para os conselhos de saúde em seus portais, cinco utilizaram a página para dar informações gerais como localização, horário de atendimento e legislações sobre o controle social. Oito deles apresentavam também as atas e as pautas de reuniões bem como suas resoluções. Apenas quatro tinham em suas páginas do conselho de saúde, além de informações gerais, atas, pautas de reuniões e resoluções, os instrumentos de gestão.

Sete conselhos municipais (25\%) mantinham páginas fora daquela da secretaria de saúde do município e para dois destes, este era o seu único endereço, ja que não possuíam página vinculada à secretaria de saúde do município. O mecanismo de busca Google revelou que 22 conselhos municipais de saúde $(81 \%)$ possuem perfil na rede social Facebook, dos quais nove (33\%) não possuem página do conselho vinculada à da secretaria de saúde de seus municípios e sete mantinham blogs externos ao portal institucional. O blog de Manaus, por exemplo, apresenta

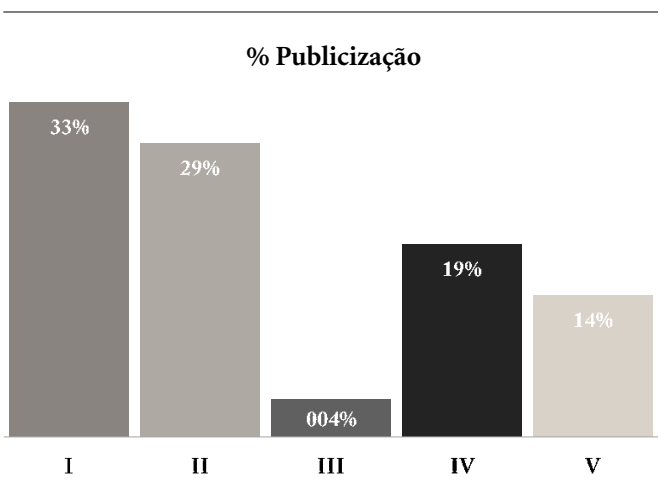

Figura 2. Publicização dos conselhos de saúde e instrumentos de gestão nos portais das capitais. informações completas e atualizadas com os instrumentos de gestão, o que não ocorria no seu portal.

Tendo em vista o protocolo de busca proposto para investigação, três municípios [(Palmas (TO), Vitória (ES) e Campo Grande (MS)] foram classificados como I por não apresentar a sua página do conselho vinculada à das secretarias de saúde, mas sim a outras abas do portal do município.

No geral, observou-se que $38 \%$ dos portais disponibilizam os instrumentos de gestão do SUS. Já no sistema SARGSUS, no período analisado, tem-se que quinze capitais apresentaram todos os três instrumentos, doze deixavam de apresentar pelo menos um deles e quatro não faziam referência a nenhum.

Os resultados encontrados nos portais e no sistema SARGSUS estão detalhados no Quadro 2. Vê-se que oito capitais classificadas como I ou II (sem os instrumentos em seus portais) estavam com as publicações completas e em dia no SARGSUS. Já nove capitais que foram classificadas

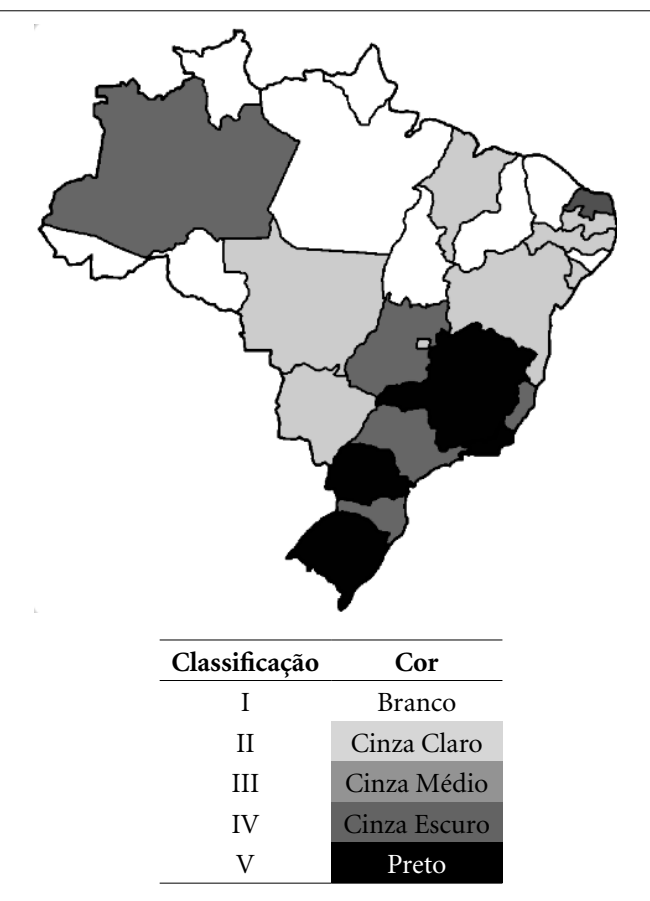

Figura 3. Mapa das UFs com as classificações propostas na pesquisa.

Fonte: Desenvolvido a partir de http://www. desenhosparacolorir24.com/escola-e-aprendizado/geografia-emapas/Brazil\#colorThis 
Quadro 2. Visibilidade dos Conselhos e instrumentos de gestão nos portais das capitais e no sistema SARGSUS.

\begin{tabular}{|c|c|c|c|c|}
\hline \multirow{2}{*}{ Capital - UF } & \multirow{2}{*}{$\begin{array}{c}\text { Classificação } \\
\text { Portal Web } 2017\end{array}$} & \multicolumn{3}{|c|}{ Sistema SARGSUS 2016} \\
\hline & & RAG & PMS (2013-2017) & PAS 2017 \\
\hline Aracaju - SE & II & Sim & Sim & Sim \\
\hline Belém - PA & I & Sim & Não & Não \\
\hline Belo Horizonte - MG & $\mathrm{V}$ & Sim & Sim & Não \\
\hline Boa Vista - RR & I & Sim & $\operatorname{Sim}$ & $\operatorname{Sim}$ \\
\hline Campo Grande - MS & II & Sim & $\operatorname{Sim}$ & $\operatorname{Sim}$ \\
\hline Cuiabá - MT & II & Sim & Sim & Sim \\
\hline Curitiba - PR & $\mathrm{V}$ & Sim & Sim & Sim \\
\hline Brasília - DF & II & Sim & $\operatorname{Sim}$ & Não \\
\hline Florianópolis - SC & IV & Sim & Sim & Não \\
\hline Fortaleza - CE & I & Sim & Sim & Sim \\
\hline Goiânia - GO & IV & Sim & $\operatorname{Sim}$ & $\operatorname{Sim}$ \\
\hline João Pessoa - PB & II & Não & Sim & Sim \\
\hline Macapá - AP & I & Não & Não & Não \\
\hline Maceió - AL & I & Sim & Sim & $\operatorname{Sim}$ \\
\hline Manaus - AM & IV & Sim & Sim & Sim \\
\hline Natal - RN & III & Sim & Sim & Sim \\
\hline Palmas - TO & I & Sim & Sim & Sim \\
\hline Porto Alegre- RS & $\mathrm{V}$ & Não & Não & Não \\
\hline Porto Velho - RO & I & Não & Não & Não \\
\hline Recife - PE & II & Sim & Sim & Não \\
\hline Rio Branco - AC & I & Não & Não & Não \\
\hline Rio de Janeiro - RJ & $\mathrm{V}$ & Sim & Sim & Sim \\
\hline Salvador - BA & II & Sim & Sim & Sim \\
\hline São Luís - MA & II & Sim & Sim & Não \\
\hline São Paulo - SP & IV & Não & Sim & Sim \\
\hline Teresina - PI & I & Sim & Sim & Não \\
\hline Vitória - ES & IV & Sim & Sim & Sim \\
\hline
\end{tabular}

como I ou II apresentaram lacunas nas publicações. No outro extremo, dentre as nove capitais classificadas como IV ou V, quatro apresentaram lacunas nas publicações no SARGSUS.

\section{Discussão}

Um dos postulados da democracia é o direito ao acesso à informação, condição sine qua non da participação política em condições de igualda$\mathrm{de}^{27}$. Somente uma sociedade informada dos assuntos de relevância política ou interesse público pode agir em conformidade para utilizar os mecanismos de participação política ${ }^{40}$.

Por meio dos portais institucionais, o Estado pode dispor informações e serviços aos cidadãos, estejam eles dispostos ou não em localidades remotas e de difícil acesso ${ }^{41}$, permitindo ampliar a sua participação política no processo decisório ${ }^{42}$.

Os resultados da presente pesquisa demonstram dificuldades de publicização tanto dos conselhos de saúde quanto dos documentos que balizam o planejamento, a execução e o monitoramento da política de saúde. Sendo os portais propriedade do governo, os resultados dão peso às percepções dos conselheiros de que o conselho de saúde ainda está atrelado às ações da gestão ${ }^{43}$ e ainda, em parte, de que possuem pouca visibilidade para a sociedade $24,25,44$. Como visto, $37 \%$ dos portais das capitais não trouxeram páginas referentes ao conselho de saúde e $29 \%$ dos que disponibilizaram, traziam somente informações genéricas sobre telefone, local e o que é o controle social.

A Resolução 453/2012 do Conselho Nacional de Saúde determina que as três esferas de governo garantam a autonomia administrativa para o 
pleno funcionamento do conselho de saúde com dotação orçamentária, autonomia financeira e organização da secretaria-executiva. Isso inclui a infraestrutura e o apoio técnico bem como os meios para viabilizar canais de informações com os cidadãos representados. Se as instituições participativas irão ter um efeito nas decisões, então seu funcionamento precisa estar aberto a escrutínio não só para os participantes, mas também para o público em geral ${ }^{45}$.

Os resultados da pesquisa apontam que os conselhos buscam estabelecer um canal de informação e isso foi retratado quando $81 \%$ dos conselhos mantêm perfis em redes sociais como o Facebook e outros sete alimentam blogs externos ao portal. Para Castells ${ }^{46}$, as novas tecnologias estão integrando o mundo em redes globais e esta formação em rede permite uma maior mobilidade e versatilidade no trânsito da informação. Isso torna a comunicação mais fluída e dinamiza a troca de informações "rompendo com o modelo hierárquico tradicional da burocracia empresarial ou estatal" ${ }^{\prime 4}$.

A necessidade de transpor a burocracia estatal foi buscada por nove conselhos que não possuíam sites "institucionais", mas sim páginas do Facebook. Estas manifestações em redes sociais, blogs e outros ambientes (inclusive offline) permitem democratizar e descentralizar o controle, a produção e a circulação das informações ${ }^{48}$.

Olhando de forma mais atenta ao conteúdo das páginas dos conselhos, 12 apresentaram em suas páginas informações pertinentes às suas ações, decisões e estrutura, ampliando assim as oportunidades de informar os cidadãos e assegurar o caráter público dos debates e decisões ${ }^{49}$. Estes resultados estavam de acordo com a portaria MS/GM 1.802/2009 que orienta os conselhos em seu artigo $6^{\circ} \S 5^{\circ}$ sobre o que informar à população: I - formas de participação; II - composição do conselho de saúde; III - regimento interno dos conselhos; IV - Conferências de Saúde; V - data, local e pauta das reuniões; e VI - deliberações e ações desencadeadas.

Para os teóricos da democracia, o cidadão bem informado está melhor equipado para decidir e avaliar as atividades governamentais. A transparência das ações e intenções dos agentes decisórios permite ao cidadão averiguar o cumprimento dos princípios democráticos e das regras que estabelecem o contrato social (direito de controle da sociedade civil no regime político ${ }^{42,50}$.

Os resultados demonstram que $62 \%$ das capitais brasileiras, onde, em princípio, há mais recursos disponíveis, não apresentam em seus por- tais os instrumentos de gestão do SUS (PS, RAG e PAS). E mesmo no sistema SARGSUS, instituído pelo Ministério da Saúde como lócus de publicização obrigatória dos instrumentos, $44 \%$ dos municípios não apresentaram os três instrumentos pesquisados.

A efetivação da democratização da gestão pública requer a incorporação dos conselhos como canais efetivos de participação, estabelecendo novas relações entre Estado e sociedade e, para isso, há de se buscar alterações no funcionamento da estrutura estatal e que esta esteja disposta a partilhar o poder de decisão, controle e implementação da política de saúde ${ }^{51}$.

No entanto, ainda se percebe um desarranjo do Estado para tornar acessíveis suas informações, procedimentos, decisões e, portanto, para "estabelecer relações de parceria com a sociedade" 52 . A ausência de determinadas informações, prejudica a negociação e a cogestão da política por parte dos conselheiros, o que pode reduzir esta esfera pública deliberativa a um espaço reivindicativo $^{52,53}$ ou ainda, a um ponto de passagem da política, quando deveria ser uma parada [nó $]^{14}$.

\section{Conclusão}

A presente pesquisa buscou analisar em que medida os portais das capitais das UFs brasileiras cumprem o disposto na resolução 453/2012 do Conselho Nacional de Saúde e na Lei 141/2012, no que se refere a divulgação do conselho de saúde e seus instrumentos de gestão. Para tal, foram verificadas nos portais das capitais a existência da página do conselho municipal de saúde e dos instrumentos PS, PAS e RAG.

Apesar de recomendada por lei, viu-se que a publicidade é dada de distintas maneiras pelas capitais. Ainda que o melhor cenário fosse que cada capital divulgasse a página do conselho e, dentro dela, os instrumentos que condicionam o cidadão a exercer o controle social, esta é uma realidade para apenas $14 \%$ dos investigados. O maior contingente $(33 \%)$ diz respeito aos portais que não divulgavam nem informações sobre o conselho de saúde, nem sobre os instrumentos de gestão.

Ainda que a publicidade seja obrigatória somente para o SARGSUS, é preciso buscar compreender porque os instrumentos de gestão não foram publicizados nos portais, dado o caráter institucional e a amplitude no alcance aos diferentes públicos. Num sistema que inclui a parti- 
cipação do cidadão, dar-lhe acesso à informação inteligível é questão elementar para que as assimetrias do processo decisório possam diminuir.

As lacunas encontradas neste estudo em um repertório de conteúdos informacionais centrais ao funcionamento da política de saúde sinalizam uma dificuldade a ser enfrentada no SUS para maior protagonismo do cidadão. Deixar de enfrentá-la podem levar ao enfraquecimento da institucionalidade do conselho e, com isso, da própria democracia participativa.

Limitações da pesquisa dizem respeito à metodologia escolhida para a busca da página do conselho e dos instrumentos de gestão; os descritores utilizados na busca via mecanismo do portal; e o próprio buscador em si.

\section{Colaboradores}

CL Santos, PM Santos, HF Pessali e AJ Rover participaram igualmente do delineamento da pesquisa, redação e revisão do artigo.

\section{Agradecimentos}

O presente trabalho foi realizado com apoio da Coordenação de Aperfeiçoamento de Pessoal de Nível Superior - Brasil (CAPES). Os autores gostariam de agradecer à Universidade Federal de Santa Catarina (UFSC), ao Programa de PósGraduação em Engenharia e Gestão do Conhecimento (PPGEGC) e à CAPES. 


\section{Referências}

1. Ghebreyesus T. Speech to the Chamber of Deputies' Social Security and Family Commissions. Brasília; 21 March 2018. [acessado 2018 Jun 5]. Disponível em: http://www.who.int/dg/speeches/2018/chamber-ofdeputies/en/

2. Cornwall A, Shankland A. Engaging citizens: lessons from building Brazil's National Health System. Soc Sci Med 2008; 66(10):2173-2184.

3. Barnes M, Coelho VS. Social participation in health in Brazil and England: inclusion, representation and authority. Health Expect 2009; 12(3):226-236.

4. Gragnolati M, Lindelow M, Couttolenc B. Twenty years of health system reform in Brazil: an assessment of the Sistema Unico de Saúde. Directions in Development. Washington: World Bank; 2013.

5. Koler J, Martinez MG. Participatory health councils and good governance: healthy democracy in Brazil? Int J Equity Health 2015; 14(21):1-9.

6. Brasil. Presidência da República. Lei no 8.080, de 19 de setembro de 1990. Dispõe sobre as condições para a promoção, proteção e recuperação da saúde, a organização e o funcionamento dos serviços correspondentes e dá outras providências. Diário Oficial da União 1990; 20 set.

7. Brasil. Conselho Nacional de Saúde (CNS). Sistema de Acompanhamento dos Conselhos de Saúde (SIACS). Brasília: CNS. [acessado 2018 Dez 14]. Disponível em http://conselho.saude.gov.br/web_siacs/index.html

8. Brasil. Presidência da República. Lei no 8.142 de 28 de dezembro de 1990. Dispõe sobre a participação da comunidade na gestão do Sistema Único de Saúde (SUS) e sobre as transferências intergovernamentais de recursos financeiros na área da saúde e dá outras providências. Diário Oficial da União 1990; 31 dez.

9. Moreira M, Escorel S. Conselhos Municipais de Saúde do Brasil: um debate sobre a democratização da política de saúde nos vinte anos do SUS. Cien Saude Colet 2009; 14(3):795-806.

10. Zambon V, Ogata M. Controle social do Sistema Único de Saúde: o que pensam os conselheiros municipais de saúde. Revista Brasileira de Enfermagem 2013; 66(6):921-927.

11. Tatagiba L. Os Conselhos Gestores e a Democratização das Políticas Públicas no Brasil. In: Dagnino E, organizador. Sociedade Civil e Espaços Públicos no Brasil. São Paulo: Paz e Terra; 2002. p. 47-105.

12. Shimizu HE, Pereira MF, Cardoso AJC, Bermudez XPCD. Representações sociais dos conselheiros municipais acerca do controle social em saúde no SUS. Cien Saude Colet 2013; 18(8):2275-2284.

13. Kohler JC, Martinez MG. Participatory health councils and good governance: healthy democracy in Brazil? Int J Equity Health 2015; 19:14-21.

14. Almeida C, Tatagiba L. Os conselhos gestores sob o crivo da política: balanços e perspectivas. Serv Soc Soc 2012; (109):68-92.

15. Wendhausen A, Caponi S. O diálogo e a participação em um conselho de saúde em Santa Catarina, Brasil. Cad Saude Publica 2002; 18(6):1621-1628.
16. Guizardi F, Pinheiro R. Dilemas culturais, sociais e políticos da participação dos movimentos sociais nos Conselhos de Saúde. Cien Saude Colet 2006; 11(3):797-805.

17. Gonçalves AO, Gonçalves RS, Tavares AL. O olhar dos conselheiros de saúde sobre os relatórios de prestação de contas no município de Natal (Rio Grande do Norte). Saúde Soc 2011; 20(3):659-672.

18. Paiva FS, Stralen CJV, Costa HA. Participação social e saúde no Brasil: revisão sistemática sobre o tema. Cien Saude Colet 2014; 19(2):487-498.

19. Gerschman S. Conselhos Municipais de Saúde: atuação e representação das comunidades populares. Cad Saude Publica 2004; 20(6):1670-1681.

20. Junberg C, Oliveira EM, Oliveira ESG. Capacitação para quê? O que pensam conselheiros de saúde da região Sudeste. Cien Saude Colet 2014; 19(11):45134523.

21. Kleba M, Zapirom K, Comerlatto D. Processo decisório e impacto na gestão de políticas públicas: desafios de um Conselho Municipal de Saúde. Saúde Soc 2015; 24(2):556-567.

22. Bianchi C, Nicolau SM. Trajetórias de conselheiros de saúde: refletindo sobre cultura política e participação popular. Cadernos Brasileiros de Terapia Ocupacional 2017; 25(1):53-66.

23. Pessoto UC, Nascimento R, Heimann LS. A gestão semiplena e a participação popular na administração da saúde. Cad Saude Publica 2001; 17(1):89-97.

24. Cotta RMM, Cazal M, Rodrigues J. Participação, controle social e exercício da cidadania: a (des)informação como obstáculo à atuação dos conselheiros de saúde. Physis 2009; 19(2):419-438.

25. Cotta RMM, Cazal M, Martins PC. Conselho Municipal de Saúde: (re)pensando a lacuna entre o formato institucional e o espaço de participação social. Cien Saude Colet 2010; 15(5):2437-2445.

26. Canela G, Nascimento S, organizadores. Acesso à informação e controle social das políticas públicas. Brasília: ANDI; 2009.

27. Santos M. Framework de apoio à democracia eletrônica em portais de governo com base nas práticas de gestão do conhecimento [tese]. Florianópolis: Universidade Federal de Santa Catarina; 2014.

28. Brasil. Constituição da República Federativa do Brasil de 1988. Diário Oficial da União 1988; 5 out.

29. Brasil. Lei no 12.527, de 18 de novembro de 2011. Regula $\mathrm{o}$ acesso a informações previsto no inciso XXXIII do art. $5^{\circ}$, no inciso II do $\$ 3^{\circ}$ do art. 37 e no $\$ 2^{\circ}$ do art. 216 da Constituição Federal; altera a Lei no 8.112, de 11 de dezembro de 1990; revoga a Lei no 11.111, de 5 de maio de 2005, e dispositivos da Lei no 8.159, de 8 de janeiro de 1991; e dá outras providências. Diário Oficial União 2011; $18 \mathrm{dez}$.

30. Brasil. Ministério da Saúde (MS). Portaria no 2.135, de 25 de setembro de 2013. Estabelece diretrizes para o processo de planejamento no âmbito do Sistema Único de Saúde (SUS). Diário Oficial da União 2013; 25 set. 
31. Brasil. Lei Complementar $n^{\circ} 141$, de 13 de janeiro de 2012. Regulamenta o $\$ 3^{\circ}$ do art. 198 da Constituição Federal para dispor sobre os valores mínimos a serem aplicados anualmente pela União, Estados, Distrito Federal e Municípios em ações e serviços públicos de saúde; estabelece os critérios de rateio dos recursos de transferências para a saúde e as normas de fiscalização, avaliação e controle das despesas com saúde nas 3 (três) esferas de governo; revoga dispositivos das Leis nos 8.080, de 19 de setembro de 1990, e 8.689, de 27 de julho de 1993; e dá outras providências. Diário Oficial da União 2012; 16 jan.

32. Brasil. Ministério da Saúde (MS). Portaria GM no 575 , de 29 de março de 2012. Institui e regulamenta o uso do Sistema de Apoio ao Relatório Anual de Gestão (SARGSUS), no âmbito do Sistema Único de Saúde (SUS). Diário Oficial da União 2012; 29 mar.

33. Brasil. Ministério da Saúde (MS). Manual de planejamento no SUS. Brasília: Fundação Oswaldo Cruz; 2016.

34. Vieira M, Calvo M. Avaliação das condições de atuação de Conselhos Municipais de Saúde no Estado de Santa Catarina, Brasil. Cad Saude Publica 2011; 27(12):2315-2326

35. Zambon D, Ogata MN. Configurações dos Conselhos Municipais de Saúde de uma região no Estado de São Paulo. Revista da Escola de Enfermagem da USP 2011; 45(4):890-897.

36. Demo P. Participação é conquista. Noções de Política Social Participativa. Fortaleza: Imprensa Universitária da UFCE, 1996.

37. Salvi L, Gasparin D, Yamawaki Y, Frey K, Rezende D, Hardt L. Avaliação de portais de prefeituras da Região Metropolitana de Curitiba. Informática Pública 2008; 10(1):11-27.

38. Brasil. Conselho Nacional de Saúde (CNS). Resolução $\mathrm{n}^{\circ}$ 554, de 15 de setembro de 2017. Diário Oficial da União 2017; 15 set.

39. Brasil. Resolução no 453, de 10 de maio de 2012. Diário Oficial da União 2012; 10 maio.

40. Regaña LC. El papel de las redes sociales en la formación de la voluntad popular: ¿instrumento de participación política? Revista Democracia Digital e Governo Eletrônico 2015; (13):72-86.

41. Oliveira JC, Leão AS, Magahães Filho JC. Governo eletrônico e reforma da administração pública. In: Knight T, Fernandes CCC, Cunha MA, organizadores. e-Desenvolvimento no Brasil e no mundo: subsídios e programa e-Brasil. São Caetano do Sul: Yendis Editora; 2007. p. 639-653.

42. Santos JC. Informação, democracia digital e participação política: uma breve revisão teórico-analítica. Em questão 2013; 19(2):195-216.

43. Duarte E, Machado M. O exercício do controle social no âmbito do Conselho Municipal de Saúde de Canindé, CE. Saúde Soc 2012; 21(Supl. 1):126-137.
44. Landerdhal MC, Unfer B, Braun K, Skupien J. Resoluções do Conselho de Saúde: instrumento de controle social ou documento burocrático? Cien Saude Colet 2010; 15(5):2431-2436.

45. Smith G. Democratic Innovations Designing institutions for citizen participation. Cambridge: Cambridge University Press; 2009.

46. Castells M. Sociedade em Rede. São Paulo: Paz e Terra; 1999.

47. Penteado CLC, Santos MBP, Araújo RPA. Democracia, Sociedade Civil Organizada e internet: estratégias de articulação online da Rede Nossa São Paulo. Sociologias 2014; 16(36):206-235

48. Raminelli FP, Rodegheri LB, Kessler MS, Oliveira RS. A influência da internet na construção de movimentos sociais em defesa da democratização das comunicações e da sua regulamentação no Brasil. Revista de Informação Legislativa 2015; 52(205):127-146.

49. Almeida D, Cunha E. A análise da deliberação democrática: princípios, conceitos e variáveis relevantes. In: Pires R, organizador. Efetividade das instituições participativas no Brasil: estratégias de avaliação. Brasília: Ipea; 2011. p. 109-124.

50. Vedel T. L'Idée de democratie électronique: origines, visions, questions. In: Pascal P, organizador. Le Désenchantement démocratique. La Tour d'Aigues: Editions de l'Aube; 2003. p. 243-266. [acessado 2020 Set 9]. Disponível em: http://citeseerx.ist.psu.edu/viewdoc/ download?doi $=10.1 \cdot 1.177 .3493 \&$ rep $=$ rep $1 \&$ type $=$ pdf

51. Carneiro C. Conselhos de políticas públicas: desafios para sua institucionalização. In: Saraiva E, Ferrarezi E, organizadores. Políticas públicas: coletânea. Brasília: ENAP; 2006. p. 149-166.

52. Carvalho MCAA. Participação social no Brasil hoje. Pólis Papers 1998; 2:27 página(s). [acessado 2008 Set 12]. Disponível em: http://www.polis.org.br/uploads/841/841.pdf

53. Herkenhhoff MB, Rabelo DC. Controle social e direito de acesso à informação - considerações a partir da política de Assistência Social. Textos \& Contextos 2011; 10(1):20-25.

Artigo apresentado em 03/07/2018

Aprovado em 15/04/2019

Versão final apresentada em 17/04/2019 
